\title{
Arteriosclerosis in Swine Animal Model: an Alternative View to Cholesterol Hypothesis of Atherogenesis
}

\author{
Takayoshi ToDA* and Fred A. KumMERow**
}

The diet of animal models can be manipulated so as to accelerate the arterial lesions for comparative studies between man and animals ${ }^{1-4)}$. The current view" on dietary "risk factors" is overwhelmingly focused on serum cholesterol level, although many other factors are involved in the development of atherosclerosis.

Results obtained in our department are summarized here and possible pertinence in atherogenesis are discussed together with relevant data by other investigators.

A) The aging of arteries in swine on a non-atherogenic diet

Arteriosclerosis has been considered to be a function of the aging process ${ }^{6}$. The arterial system is an organ which involver the same aging phenomenona such as fertilization, growth and involution as in other systems ${ }^{7,8)}$. Intimal lesions including diffuse intimal thickening and intimal cushions occur in the arteies of aged swine just as in other animals ${ }^{9-12)}$ (Fig. 1). The thickened intima contains mature smooth muscle cells and degenerate cells with or without stainable lipid. The origin of these intimal smooth muscle cells has not yet been clarified. However, some smooth muscle cells were occasionally observed passing through fenestrations of the internal elastic lamina. Intimal cell nests were sometimes associated with marked fibrinous deposits near the branching site of the coronary arteries. These intimal cell nests appeared to be derived from the endothelial lining ${ }^{13)}$. Hematogenous cells such as monocyte, macrophage, lymphocyte, granular leucocytes and

* Department of Pathology, School of Medicine, Ryukyu University Okinawa, Japan

** Department of Food Science, Burnsides Research Laboratory, University of Illinois, U.S.A. mast cells were sometimes seen in the subendothelial spaces. Studies have been focusing on the interaction between hematogenous cells and the arterial wall from the immunological aspects.

B) The endothelium as a protective component of the arterial wall

Rapid induction of intimal thickening is accomplished by the occurence of intimal modified smooth muscle cells ${ }^{14-16)}$. One mechanism causing the increase in number of such modified smooth muscle cells has been reported as being the migration of medial smooth muscle cells ${ }^{17-19}$. Webster et al. ${ }^{16)}$ reported that intimal cells could increase by cell division after mechanical injury to the rabbit aorta. We studied the ultrastructural features and frequency of mitotic intimal cells in the thickend intima of the swine aorta after a mechanical denudation procedure using an inflated embolectomy ballon catheter ${ }^{20}$. The aortic surface at one day after having been rubbed with the inflated ballon catheter was denuded of endothelium over large areas. Immediately after denudation, the aortic surface bacame covered with a layer of attached platelets. Many dead cells were noted adjacent to the denuded surface.

After three days, the exposed surface was covered with platelets, fibrin, leucocytes and one or two cell layers of modified smooth muscle cells. A small number of mitotic modified smooth muscle cells were observed (Fig. 2) on the exposed surface $(2 / 352$ or $0.2 \%)$. Mitotic medial smooth muscle cells were also noted near dead cells and were frequently seen in the inner media within the first three cell layers $(87 / 1825$ or $4.6 \%)$ but were infrequent in the deep media.

After two weeks, endothelial cells covered much of the thickened intima, but modified smooth 


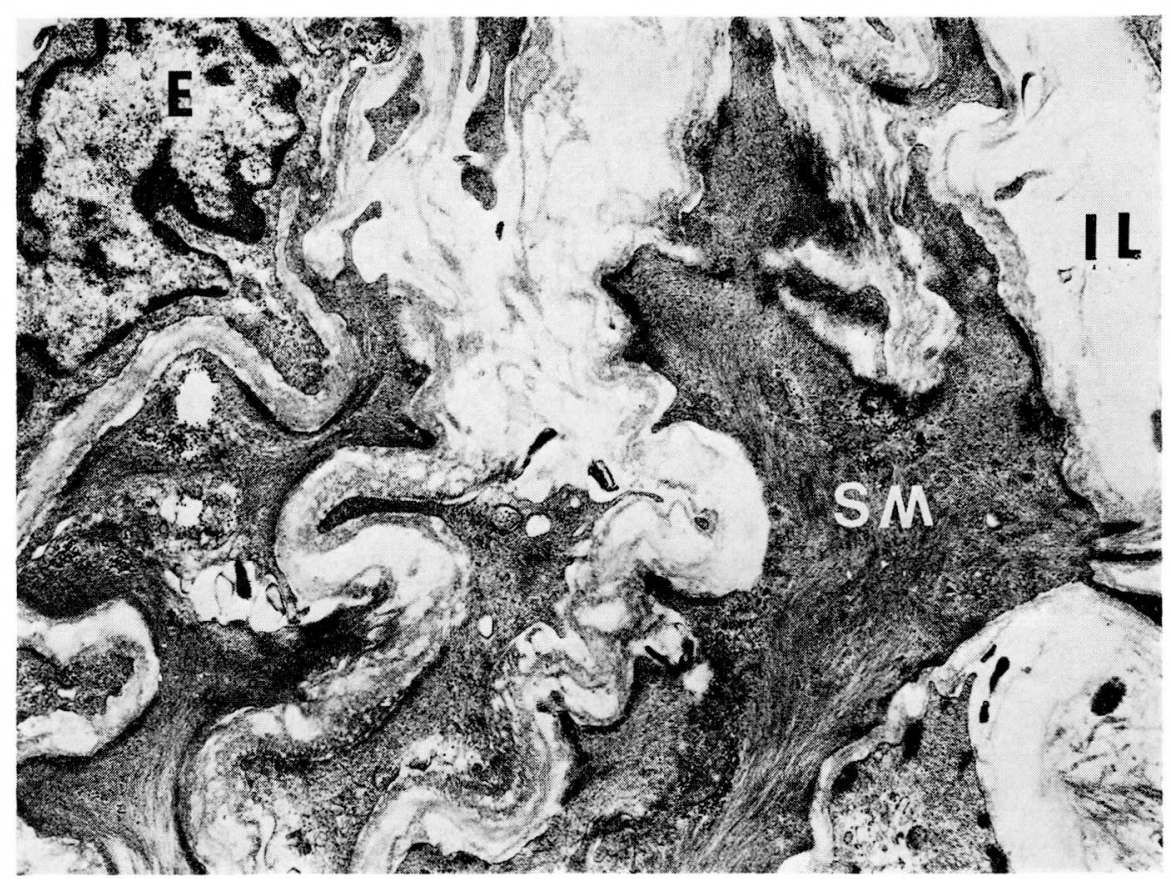

Fig. 1 Six month-old swine coronary artery.

Several smooth muscle cells (SM) are present in the subendothelial space $(\times 12,800)$. E: endothelial cell. IL: internal elastic lamina.

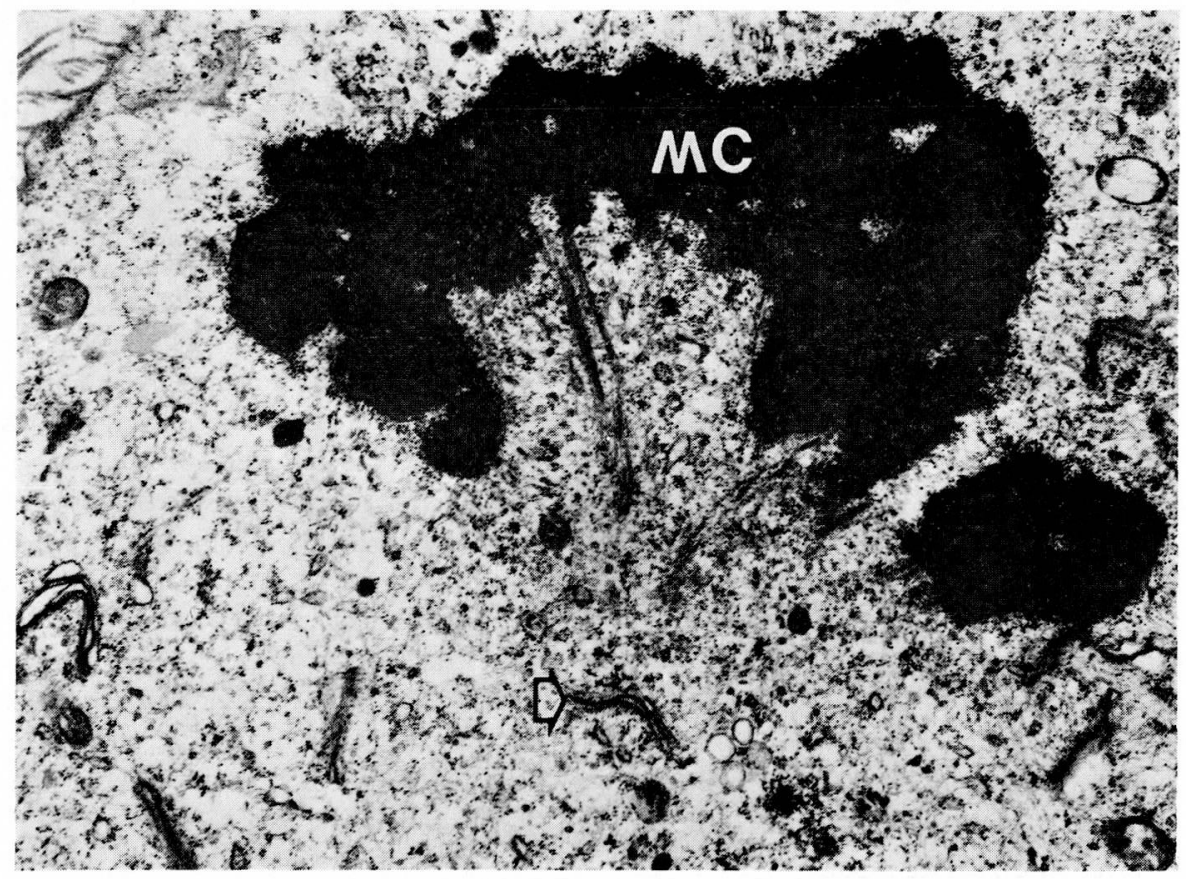

Fig. 2 A mitotic intimal cell (MC) with paired cisternae (arrow) in the swine aorta $(\times 12,800)$. 


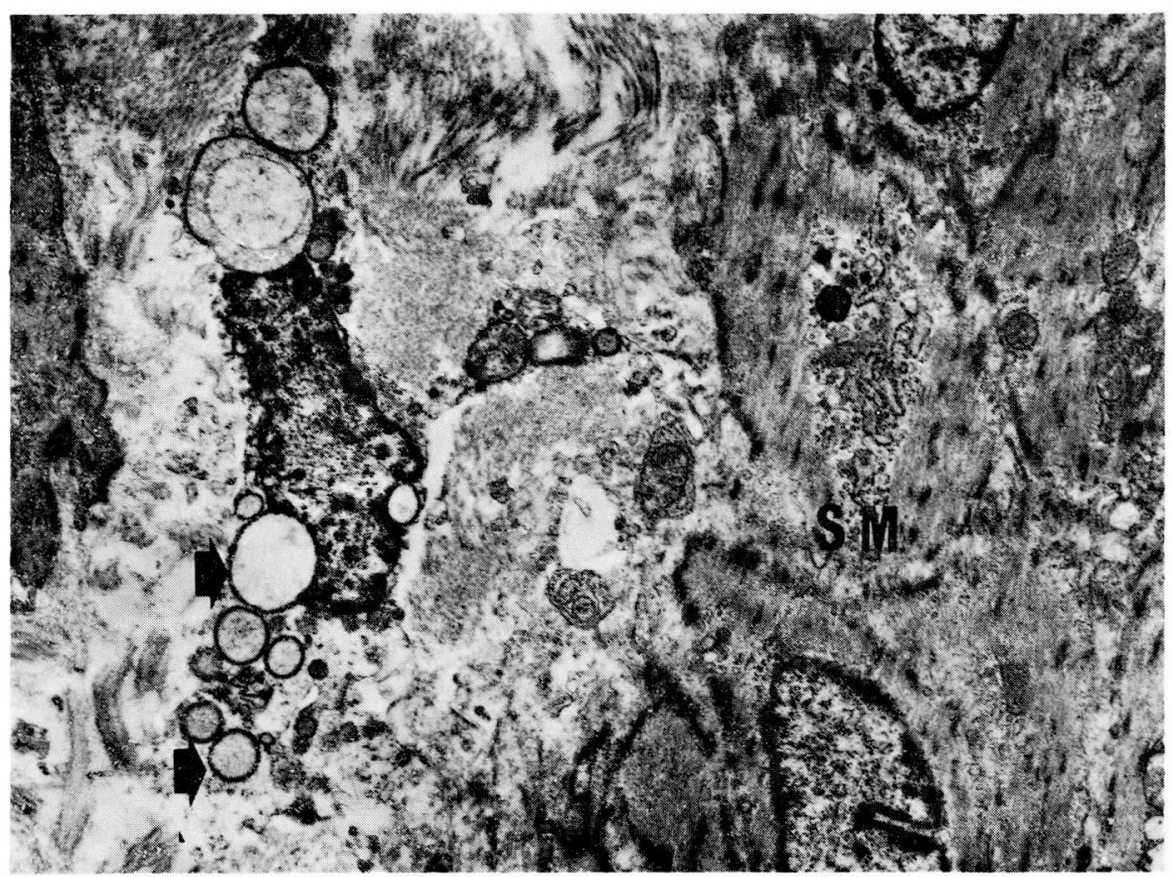

Fig. 3 Note a degenerate cell containing numerous membrane-bound vacuoles (arrow), some of which are immersed into stromal debris $(\times 7,200)$.

SM: smooth muscle cell.

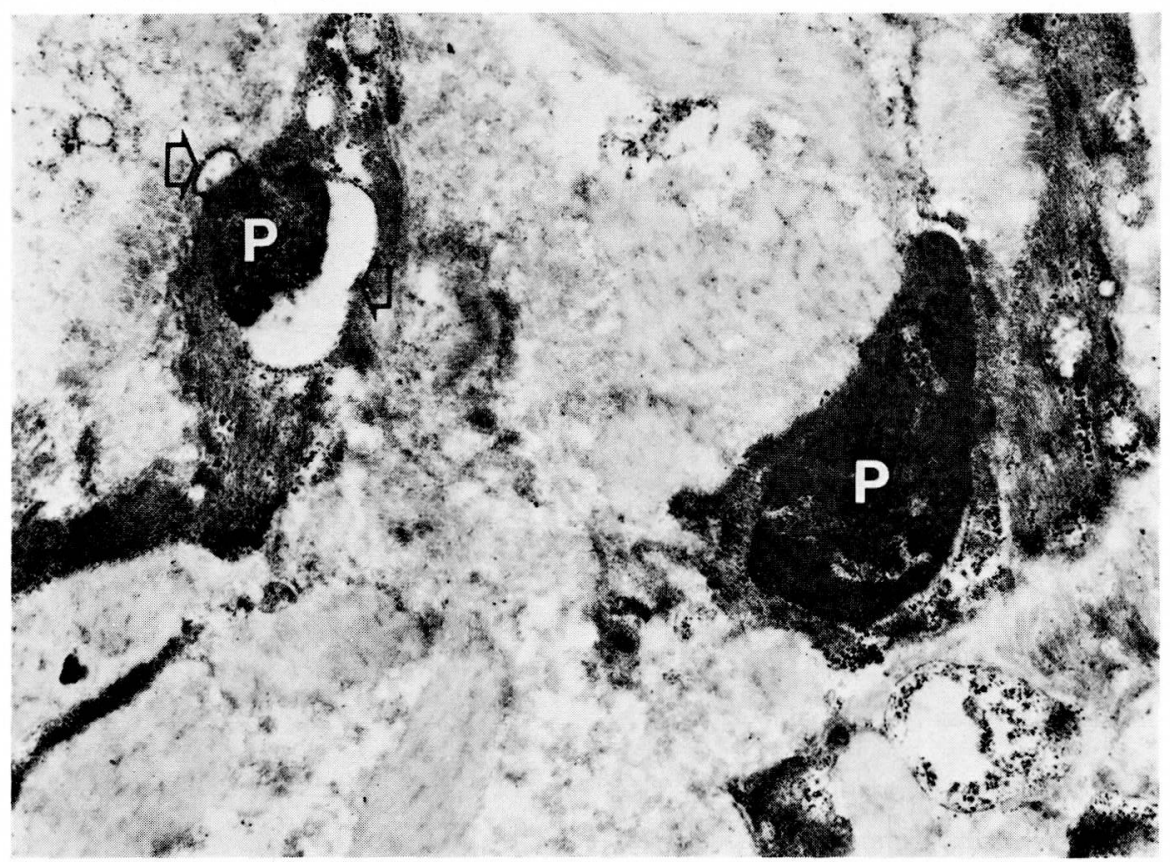

Fig. 4 Degenerate smooth muscle cells with pyknotic nuclei (P) and vacuoles (arrow) $(\times 12,000)$. 
muscle cells still remained in small areas. The thickened intima contained modified smooth muscle cells and macrophages. Mitosis of intimal cells were occasionally observed at this period $(3 / 582$ or $0.5 \%$ ). Fibrin, platelets, and red and white blood cells were no longer present.

After 4 weeks, regenerated endothelial cells completely covered the thickened intima. The intimal smooth muscle cells at this period displayed similar cytological features as those of the media.

Our data suggest that intimal smooth muscle cells are initially derived from the media, and they multiply mainly by mitosis. Further studies are warranted for evaluation of the control of endothelial growth and the role of endothelial injury in the pathogenesis of atherosclerosis ${ }^{21)}$.

\section{C) Hypoxic effect on vascular smooth muscle cells}

The inner arterial wall usually lacks vasa vasorum so oxygen must come by diffusion from the circulating blood. Whereat ${ }^{22}$ ) has suggested that the thickeness of the intima is a critical factor for diffusion of oxygen. Metabolic studies with strips of swine aorta ${ }^{23)}$ indicate that oxygen supply influences the rate of lipid synthesis. In vitro studies of gwine aorta suggested that less labeled acetyl coenzyme A was converted to lipid and less labeled oleic acid was incorporated when the oxygen supply was optimum ${ }^{23)}$. Zollinger ${ }^{24)}$ described the morphological changes of ductus arteriosus as "adaptive intimal sclerosis" due to "a decrease in blood flow", while hypoxia has been recognized as being an atherogenic factor.

Our previous studies ${ }^{25,26)}$ showed that intimal smooth muscle cells appeared in the subendothelial space in the swine ductus arteriosus around early gestational age. These smooth muscle cells seemed to migrate from the media because their cytoplasmic connection to each other. Frequent mitotic smooth muscle cells were also seen in the media. Intimal smooth muscle cell growth progressed with age. Ductus arteriosus from 6 month-old swine had a ligament-like macroscopic appearance and contained a lot of degenerate smooth muscle cells, cell debris, and collagen fibers. Degenerate smooth muscle cells frequently contained abundant vacuoles and dilated rough endoplasmic reticulum (Fig. 3).

Specimens from the hepatic side of the ductus venosus contained normal smooth muscle cells, while samples from the portal side of the ductus venosus displayed severe degeneration of medial smooth muscle cells (Fig. 4). This is consistent with the report that the hepatic side of ductus venosus closes more slowly than the portal side ${ }^{27)}$.

Thus, the morphology of ductus closure and atherosclerosis share a similar basic process, of intimal smooth muscle cell growth, degeneration of smooth muscle cells, accumulation of fibrinous protein, and endogenous lipid production ${ }^{28,29)}$.

\section{D) Dietary fats and atherosclerosis}

The effect of polyunsaturated fatty acids has generally been considered in term of the ratio of polyunsaturated $(\mathrm{P})$ to saturated $(\mathrm{S})$ fats in the diet, the $\mathrm{P} / \mathrm{S}$ ratio ${ }^{30-32}$ ). A low $\mathrm{P} / \mathrm{S}$ ratio, which shows up in a relatively low percentage of polyunsaturated fatty acids in the red blood cells ${ }^{33}$ ), is one of the important indicators in coronary heart disease.

This view seems to be supported by epidemiological studies such as that of the Intersociety Commission for Heart Disease Resources that reported a direct correlation between the percentage of total dietary calories obtained from saturated fats and the incidence of coronary heart diseases in various population groups ${ }^{34}$. Yet, a strikingly similar correlation can also be found between the incidence of coronary heart disease and the intake of the isomeric fatty acid, or trans-fatty acids, that are present in hydrogenated vegetable fat products such as margarines ${ }^{35}$.

In the USA, the rapid growth of the soybean oil industry has provided an economical source of vegetable oil to the American diet. Approximately $28 \mathrm{lbs} / \mathrm{capita} / \mathrm{yr}$ of this oil is presently consumed

Table 1 Plasma lipid levels in experimental groups

\begin{tabular}{clcc}
\hline & & $\begin{array}{c}\text { Total } \\
\text { cholesterol } \\
(\mathrm{mg} / \mathrm{d} l)\end{array}$ & $\begin{array}{c}\text { Trigly- } \\
\text { cerides } \\
(\mathrm{mg} / \mathrm{d} l)\end{array}$ \\
\hline 1st exp. & B-group & $70.1 \pm 15.3$ & $43.4 \pm 19.1$ \\
& CH-group & $77.8 \pm 20.0$ & $46.6 \pm 17.6$ \\
2nd exp. & CO-group & $82.6 \pm 13.8$ & $67.2 \pm 37.2$ \\
& B-group & $84.2 \pm 23.2$ & $55.6 \pm 10.5$ \\
& BM-group & $86.4 \pm 16.1$ & $75.4 \pm 9.1$ \\
3rd exp. & BB-group & $118.1 \pm 14.9$ & $65.9 \pm 7.4$ \\
& HS-group & $114.5 \pm 13.3$ & $72.6 \pm 13.3$ \\
& SAF-group & $116.2 \pm 23.2$ & $96.7 \pm 17.5$ \\
4rth exp. & LA-group & $132.6 \pm 18.3$ & $81.5 \pm 19.3$ \\
& B-group & $93.4 \pm 9.3$ & $54.2 \pm 13.5$ \\
& BM-group & $105.3 \pm 16.7$ & $56.4 \pm 21.3$ \\
& BB-group & $192.3 \pm 25.1$ & $66.1 \pm 15.3$ \\
\hline
\end{tabular}

Data are expressed as mean \pm standard deviation. 
as shortening, frying oil and margarine ${ }^{34)}$. The isomeric trans-fatty acids have been thought to influence the properties of cell membranes ${ }^{36)}$, decrease the oxidation of lipids (oleic acid) in the rat heart mitochondria ${ }^{37,38)}$ and increase the incidence of atherosclerosis in animal models ${ }^{39}$.

Several experiments were carried out in our laboratory for the purpose of researching the role of dietary fats in the development of coronary atherosclerosis. Table 1 indicates plasma lipid plofiles in various experimental groups. In the first experiment, no significant coronary arterial lesions were seen in the swine which were fed a diet containing either $1 \%$ cholestero ( $\mathrm{CH}$-group) or $10 \%$ corn oil (CO-group) when compared to the basal dietfed group (B-group).

In the second experiment ${ }^{40)}$, three groups of two-month-old swine were fed either a basal diet (B-group) or a basal diet containing $8.3 \%$ margarine (BM-group) or butter (BB-group) for 4 months. Total content of polyunsaturated fatty acid in the diets was $58.4,14.0$, and $30.2 \%$ in the $\mathrm{B}, \mathrm{BM}$, and $\mathrm{BB}$ groups respectively. The groups of swine which were fed either margarine or buttercontaining diets showed an increase in the degree of intimal thickening of the coronary arteries. However, there was no significant difference in the coronary arteries of the BM and BB groups.

The third experiment included three groups, the HS-, SAF-, and LA-groups ${ }^{41)}$. Each experimental group diet contained $20 \%$ fat. The level of linoleic acid in the diets was adjusted to be sufficient for the growing animals and ranged from 11.2 to 17.6 percent. The fatty acid composition of these diets was: HS-group 16:0-18.7, 18:0-19.7, 18:1 trans-29.2, 18: 1 cis-11.1, 18: 2 w 6-17.6, 18: 3 w $3-$ 2.1; SAF-group 16:0-3.9, 16:1 w 7-0.1, 18:0$2.1,18.1$ trans-0.1, $18: 1$ cis-76.6, $18: 2$ w $6-15.5$, 18: 3 w 3-0.1, 20: 1 w 9-0.3; LA-group 16: 0-23.6, $16: 1$ w 7-1.9, 18: 0-14.5, 18: 1 trans-0.8, 18.1 cis$46.1,18: 2$ w $6-11.2,18: 3$ w 3-0.3, $20: 2$ w 6-0.5, 20: 4 w 6-0.2.

The SAF-group had the most severe coronary arterial lesions and the HS-group had the least severe lesions (Fig. 5).

In the fourth experiment, $20 \%$ margarine or butter containing diets were fed to 2 month-old swine for 4 months. The butter supplemented group (BB-group) had more lipid-rich coronary arterial lesions than the margarine supplemented

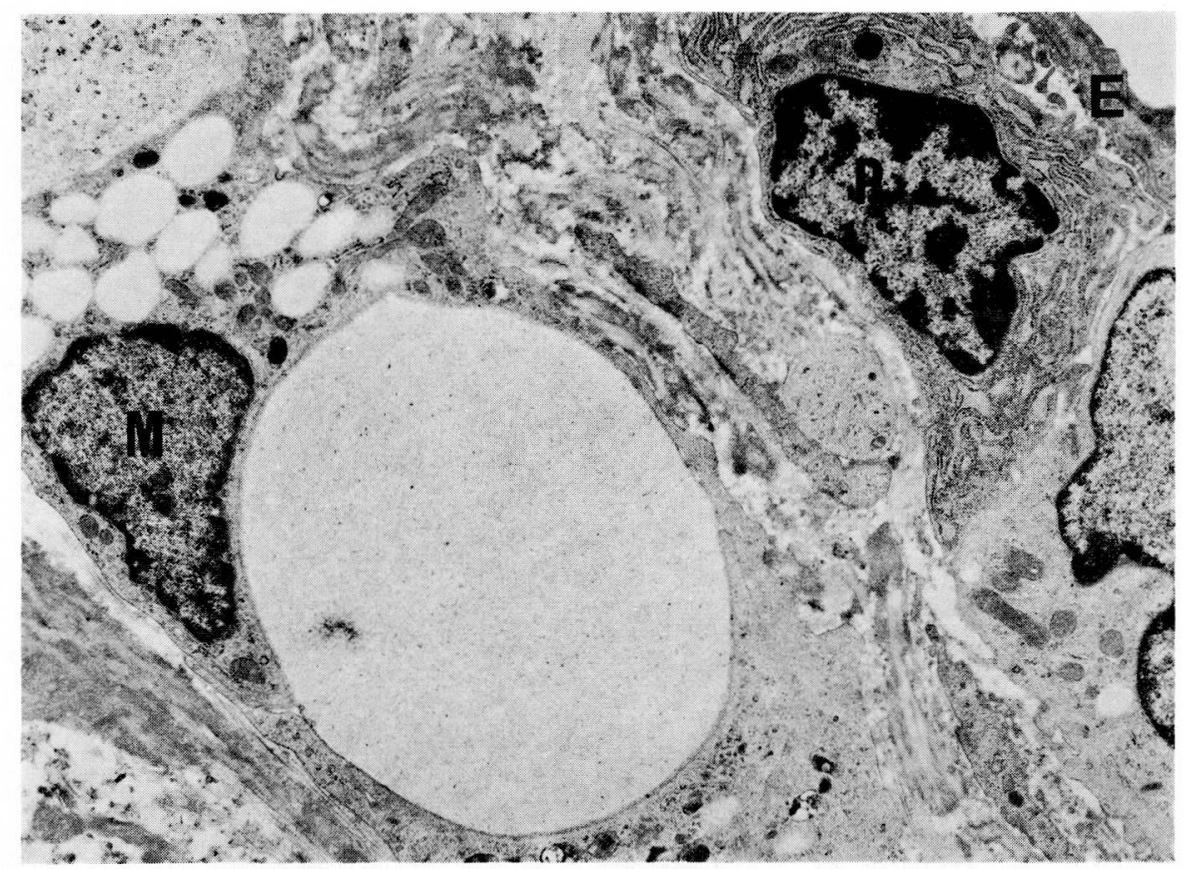

Fig. 5 Coronary artery from SAF-group.

A lipid-containing macrophages $(M)$ and plasma cell $(P)$ are shown $(\times 5,400)$.

E: endothelial cell. 


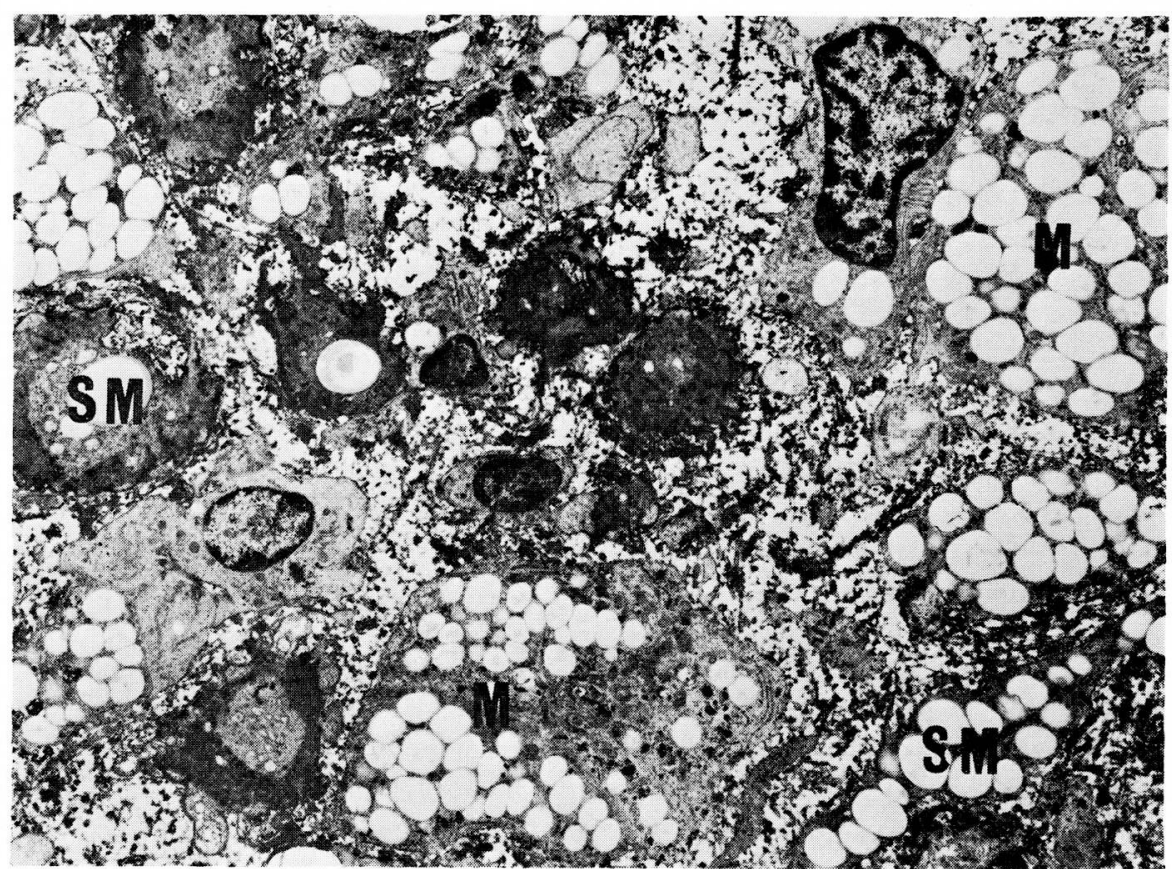

Fig. 6 Thickened intima of coronary artery from BB-group.

Numerous lipid containing macrophages (M) and smooth muscle cells (SM) are seen $(\times 2,000)$.

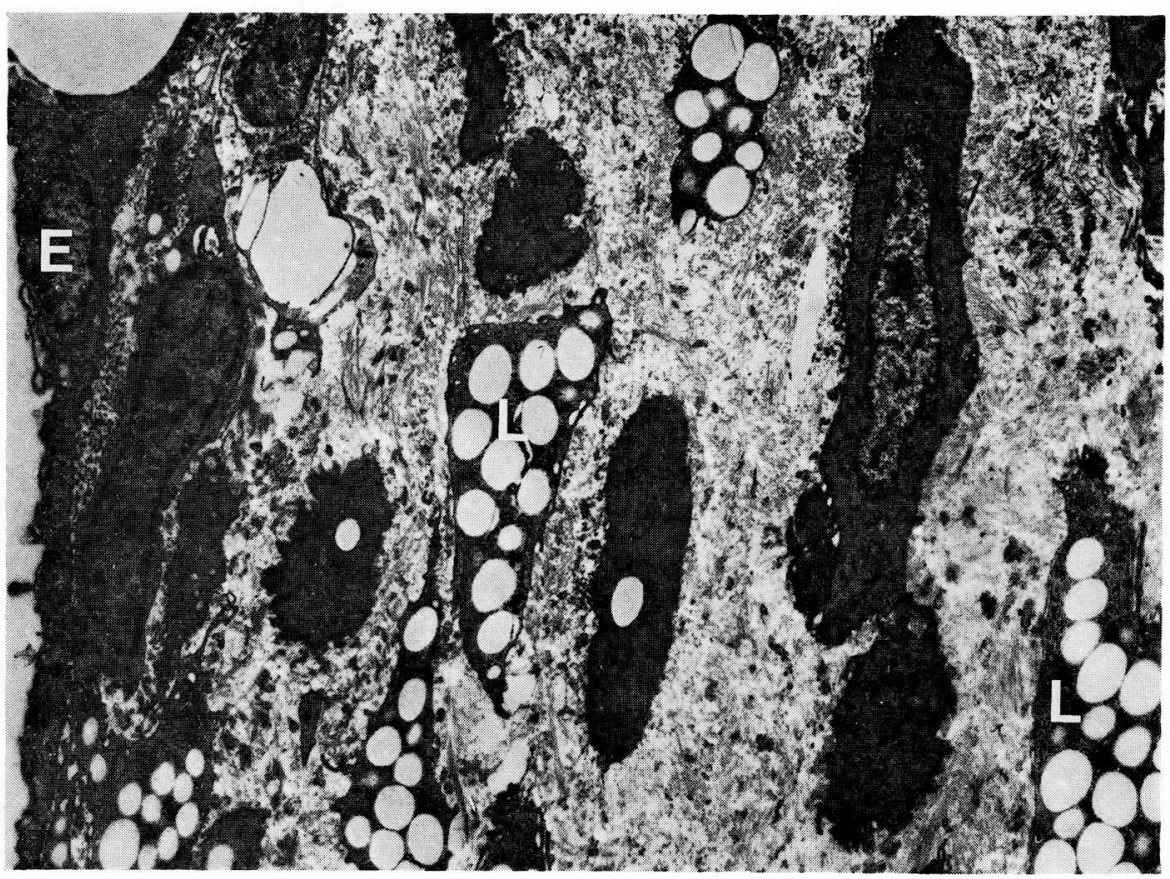

Fig. 7 Lipid-rich coronary arterial lesion from excess vitamin $D_{3}$ fed swine $(\times 3,600)$. E: endothelial cell. L: lipid-containing cell. 
group (BM-group) (Fig. 6). These results showed that trans-fatty acid may be less atherogenic in the presence of an adequate amount of linoleic acid. However, increasing dietary intake of trans-fatty acid in culinary fats may aggravate coronary arteriosclerosis $^{42)}$.

\section{E) Angiotoxicity of vitamin $D_{3}$ and dietary minor components of minerals}

The British Pediatric Association ${ }^{43)}$ reported that the incidence of diseases such as idiopathic hypercalcemia, supravalvular aortic stenosis syndrome, and renal tubular acidosis, decreased several years after vitamin D fortification of food was reduced.

Searching for the mechanism causing a high frequency of degenerate arterial cells in naturally occuring aortic lesion in commercial swine, we reexamined the commercial ration for possible causative agents. The chemist involved in vitamin $\mathrm{D}$ assay at the Food and Drug Administration (FDA), Mike Deutsch and Walter Hooper, collaborated by assaying for vitamin $\mathrm{D}$ in various samples of rations and tissues. They found 14 times more vitamin $\mathbf{D}$ than the amount recommended by the National Research Council (NRC) in commercial swine rations ${ }^{44}$.

A survey commissioned by the FDA ${ }^{45)}$ verified that the American diet contained 2,400 IU of vitamin D per capita per day, an amount 6 times higher than $400 \mathrm{IU} /$ day recommended for babies and children. This dietary level may have decreased since FDA in now mandating the removal of vitamin $\mathbf{D}$ from rice and cereals. Vitamin $\mathrm{D}$ is, however, still being added in excessive amounts to livestock rations. The meat from such livestock contains substaintial levels of vitamin $\mathrm{D}$ as shown by bioassay of meat products by the $\mathrm{FDA}^{44)}$.

The trial feeding of $62,500 \mathrm{IU}$ of vitamin $\mathrm{D}_{3} / \mathrm{kg}$ of cholesterol-free ration for 3 months produced severe occlusion in swine coronary arteries. Serum cholesterol levels in the animals with or without atherosclerotic lesions showed no differences and were unrelated to the development of lesions ${ }^{1)}$.

The coronary arterial lesions in the swine initially fed excess vitamin $D$, and subsequently fed the normal commercial ration showed the usual features of atheroma with stainable lipid, lipidcontaining cells, calcification and necrosis (Fig. 7).

An electron microscopic survey of atherosclerotic lesions showed mitotic figures of endothelial, intimal and medial smooth muscle cells. Mitotic cells in the media were often located near dead cells. We indicated that 25 -hydroxy vitamin $\mathrm{D}_{3}$ has an important role in the hypervitaminosis Dinduced arterial lesions ${ }^{46}$.

In order to determine the minimum level of dietary vitamin $\mathrm{D}_{3}$ causing arterial tissue damage, four groups were fed the following levels of vitamin $D_{3}$ per ton of ration for 4 months: group A - 100,000 IU, group B - 300,000 IU, group C $2,000,000$ and group $\mathrm{D}-4,000,000 \mathrm{IU}$. The most severe intimal thickening was seen in group $D$. Those coronary arterial lesions contained degenerate cells without stainable lipid. Degenerate cells without stainable lipid were seen more frequently in the coronary arteries of group $\mathrm{C}$ than in group $\mathrm{A}$ and $\mathrm{B}^{47)}$. The concentration of 25-hydroxyvitamin $\mathbf{D}_{3}$ of the group $\mathrm{C}$ was similar to that of the American population ${ }^{48)}$. We also indicated that an excess dietary intake of vitamin $\mathrm{D}_{3}$ by pregnant animals may have potential angiotoxic effects on the coronary arteries of their offsprings ${ }^{49}$ ).

Since milk food products are fortified with vitamin $\mathrm{D}$, we tried to feed milk powder plus vitamin $\mathrm{D}$ to swine ${ }^{50)}$. Although the maximum level of dietary vitamin D was 300,000 IU per ton of diet, an amount which produced no significant arterial lesions in our previous swine experiment ${ }^{47}$, we observed an additive synergic effect upon the production of coronary arterial lesions with activated and degenerate smooth muscle cells, and lipid-containing cells.

Furthermore, magnesium deficiency aggravated the coronary arterial lesions which were induced by feeding the animals a diet supplemented with skimmed milk powder and vitamin $\mathrm{D}_{3}$ (unpublished data). Further studies are required to disclose how dietary vitamin $\mathrm{D}_{3}$ and minor components of minerals interact on the arterial wall.

\section{Acknowledgement}

This study was supported in part by a grant from the Ministry of education, Science and Culture of Japan and the Burnsides Research fund.

\section{References}

1) Taura, S., Taura, M., Imai, H. and Kummerow, F. A.: Coronary atherosclerosis in normocholesterolemic swine artery. Artery, 4: 395 (1978).

2) Kamio, A., Huang, W. Y., Chow, B. H. S., Imai, H. and Kummerow, F. A.: Aortic intimal changes in aging swine. Paroi Arteielle, 4: 27 (1977).

3) Huang, W. Y., Kamio, A., Yeh, W.-J. and Kummerow, F. A.: The influence of vitamin D on 
plasma and tissue lipids and atherosclerosis in swine. Artery, 3: 439 (1977).

4) Cho, B. H. S., Taura, S. and Kummerow, F. A.: Subcellular distribution of ${ }^{3} \mathrm{H}$-cholesterol in the arterial, heart, and liver tissue of swine in vitro. Artery, 4: 528 (1978).

5) "Healthy People," the Surgeon General's Report on Health Promotion and Disease Prevention. U.S. Government Printing Office, Washington, D.C. (1979).

6) Nakashima, T. and Tanikawa, J.: A study of human aortic distensibility with relation to atherosclerosis and aging. Angiology, 22: 447 (1971).

7) Toda, T.: Histometrical approach of aging proccesses on rat aorta using low power magnification photograph of electron microscopy. Acta. Med. Nagasaki, 23: 63 (1978).

8) Toda, T., Tsuda, N., Nishimori, I., Leszczynski, D. E. and Kummerow, F. A.: Morphometrical analysis of the aging process in human arteries and aorta. Acta Anat., 106: 35 (1980).

9) Kamio, A., Cho, B. H. S., Kummerow, F. A. and Takebayashi, S.: Light and electron microscopic studies of diffuse intimal thickening in young and aging swine aortae. Med. Bull. Fukuoka Univ., 3: 377 (1976).

10) Taura, S., Taura, M., Tokuyasu, K., Kamio, A. and Kummerow, F. A.: Ultrastructure of aortic intima obtained as a by-product of coronary bypass surgery. Artery, 3: 529 (1977).

11) Kamio, A., Huang, W. Y., Imai, H. and Kummerow, F. A.: Mitotic structures of aortic smooth muscle cells in swine and in culture; paired cisternae. J. Electron Microsc., 26: 29 (1977).

12) Taura, S., Taura, M., Tokuyasu, K., Kamio, A., Kummerow, F. A. and Cleaveland J. C.: Human arterio- and atherosclerosis; identical to that in a 6 and 36 month-old swine fed a corn soy diet free of cholesterol and saturated fat. Artery, 4: 100 (1978).

13) Moriuchi, A., Imai, H. and Kummerow, F. A.: Ultrastructural studies of coronary arterial intimal. I. Intimal cell nest and serofibrinous insudation in 6-month-old swine. Exp. Molec. Pathol., 36: 19 (1982).

14) Spiro, D., Lattes, R. G. and Wiener, J.: The cellular pathology of experimental hypertension. I. Hyperplastic atherosclerosis. Am. J. Pathol., 47: 19 (1965).

15) Esterly, J. A., Glagov, S. and Fergusson, D. J.: Morphogenesis of intimal obliterative hyperplasia of small arteries in experimental pulmonary hypertension. Am. J. Pathol., 52: 325 (1968).

16) Webster, W. S., Bishop, S. P. and Geer, J. C.: Experimental aortic intimal thickening. Am. J. Pathol., 76: 245 (1974).

17) Buick, R. C.: Intimal thickening after ligature of arteries. An electron microscopy study. Circ. Res., 9: 418 (1961).

18) Schwartz, S. M., Stemerman, M. B. and Benditt, E. P.: The aortic intima II. Repair of the aortic lining after mechanical denudation. Am. J. Pathol., 81: 15 (1975).

19) Stemerman, M. B. and Ross, R.: Experimental arteriosclerosis. I. Fibrinous plaque formation in primates. An electron microscopic study. J. Exp. Med., 136: 769 (1973).

20) Taura, S., Taura, M., Kummerow, F. A., Kamio, A. and Takebayashi, S.: Mitotic structure of aortic intimal cells induced by mechanical injury in swine. Acta Pthol. Jpn., 28: 555 (1978).

21) Schwartz, S. M., Gajddusek, C. M. and Selden, S.C.: Vascular wall growth control, the role of the endothelium. Arteriosclerosis, 1: 107 (1981).

22) Whereat, A. F.: Recent advances in experimental and molecular pathology. Atherosclerosis and metabolic disorder in the arterial wall. Exp. Molec. Pathol., 7: 233 (1967).

23) Huang, W. Y. and Kummerow, F. A.: Esterification of cis and trans fatty acids by swine aortic smooth muscle cells during aerobic and hypoxic incubations. Biochem. Med., 21: 156 (1979).

24) Zollinger, H. U.: Adaptive Intimal Fibrose der Arterien. Virchows Arch (pathol. anat.), 342: 154 (1967).

25) Toda, T., Leszczynski, D. E. and Kummerow, F. A.: Morphological evidence of endogenous lipid production in swine ductus vasculature. Atherosclerosis, 37: 325 (1980).

26) Toda, T., Leszczynski, D. E. and Kummerow, F.A.: Degenerative changes in endothelial and smooth muscle cells from aging swine ductus arteriosus and venous. Amer. J. Anat., 169: 37 (1981).

27) Stewart, W. E.: The ductus venosus in the fetus and in the adult. Anat. Rec., 25: 225 (1923).

28) Briggs, R. G., Glenn, J. L.: Lipid accumulation in cells derived from porcine aorta and grown under aerobic conditions. Lipid, 11: 791 (1976).

29) Gordon, G. B., Barcza, M. A. and Bush M. E.: Lipid accumulation in hypoxic tissue culture cells. Am. J. Pathol., 88: 663 (1977).

30) Hegsted, D. E., McGandy, R. B., Myers, M. L. and Stare, F. J.: Quantitative effects of dietary fat on serum cholesterol in man. Am. J. Clin. Nutr., 17: 281 (1965).

31) Keys, A.: Coronary heart diseases in seven countries. Circulation, 41: Suppl. 1 (1970).

32) Stamler, J.: Life styles, major risk factors, proof and public policy. Circulation, 58: 3 (1978).

33) National Diet Heart Study. Circulation, 37: Suppl. (1968).

34) Kummerow, F. A.: Nutrition imbalance and angiotoxins as dietary risk factors in coronary heart 
disease. Am. J. Clin. Nutr., 32: 58 (1979).

35) Perkins, E. G., McCarthy, T. P., O. Brien, M. A. and Kummerow, F. A.: The application of packed colum gas chromatographic analysis to the determination of trans unsaturation. L. Am. Oil. Chem. Soc., 54: 279 (1977).

36) Vigo, C., Gorri, F. M., Quinn, P. J. and Chapman, D.: The modulation of membrane fluidity by hydrogenation processes. II. Homogenous catalysed model biomembranes. Biochem. Biophys. Acta, 508: 1 (1978).

37) Lawson, L. D. and Kummerow, F. A.: $\beta$-oxidation of the coenzyme A esters of elaidic, oleic and stearic acids and their full-cycle intermediates by rat heart mitochondria. Biochim. Biophys. Acta, 573: 245 (1979).

38) Lawson, L. D. and Kummerow, F. A.: $\beta$-oxidation of the coenzyme A esters of vaccenic, elaidic and petroselaidic acids by rat heart mitochondria. Lipids, 14: 501 (1979).

39) Weigensberg, B. I., McMillan, G. C. and Ritschie, A.C.: Elaidic acid: effect on experimental atherosclerosis. Arch. Pathol., 72: 358 (1961).

40) Toda, T., Mahfouz, M. M. and Kummerow, F. A.: Influence of dietary fats on ultrastructure and fatty acid composition of swine arterial tissue. Acta Pathol. Jpn., 34: 935 (1984).

41) Toda, T., Toda, Y., Yamamoto, V. and Kummerow, F. A.: Comparative study of atherogenecity of dietary trans, saturated and unsaturated fatty acids on swine coronary arteries. J. Nutr. Sci. Vitaminol., 31: 233 (1985).

42) Toda, T., Yamamoto, V. and Kummerow, F. A.: Further study of the atherogenecity of culinary fats in swine. (in publication).

43) Britisch Pediatric Association: Infantile hypercalcemia, nutritional rickets, and infantile scurvy in Great Britain. Brit. Med. J., 1: 1659 (1964).

44) Kummerow, F. A., Cho, B. H. S., Huang, W. Y., Imai, H., Deutsch, M. H. and Hooper, W. M.: Additive risk factors in therosclerosis. Am. J. Clin. Nutr., 29: 579 (1976).

45) Scientific literature reviews on generally recognized as safe (GRAS) food ingredients-vitamin D. Washington, D. C.: National Technical information Service, U. S. Department of Commerce, July (1974).

46) Toda, T., Leszczynski, D. E. and Kummerow, F. A.: The role of 25 -hydroxy-vitamin $D_{3}$ in the induction of atherosclerosis inswine and rabbit by hypervitaminosis D. Acta Pathol. Jpn., 33: 37 (1983).

47) Toda, T., Itoh, M., Toda, Y., Smith, T. and Kummerow, F. A.: Angiotoxicity of dietary vitamin $\mathrm{D}_{3}$ in swine. Fd. Chem. Toxic., 23: 585 (1985).

48) Holmes, R. P. and Kummerow, F. A.: The relationship of adequate and excessive intake of vitamin $\mathrm{D}$ to health and disease. J. Am. Col. Nutr., 2: 173 (1983).

49) Toda, T., Toda, Y. and Kummerow, F. A.: Coronary arterial lesions in piglets from sows fed moderate excess of vitamin D. Tohoku J. Exp. Med., 145: 303 (1985).

50) Toda, T. Mizoe, A., Ohishi, K., Toda, Y. and Kummerow, F. A.: Coronary arterial lesions in swine fed supplemental vitamin D with skimmed milk powder. J. Jpn. Atheroscler. Soc. (in press).

\section{Summary}

Examination of the coronary arteries and aortic tissue in swine by electron microscopy has shown that upto 6 months of age, various degree of fibrocellular intimal thickening had occured in those animals on a non-atherogenic diet. A mechanical denudation of the endothelium resulted in marked intimal thickening of the aorta, indicating that the endothelium has the role of protecting against plasma infiltration into the arterial wall. Ultrastructural study of the ductus vasculature disclosed that endogenous lipid syn- thesis can be accentuated under hypoxic condition. Lipid-rich arterial lesions, which were characterized by the presence of degenerate cells with or without stainable lipid were produced by feeding them either vitamin D or culinary fats without significant amount of cholesterol. These data suggested that other angiotoxic factors as well as hypercholesterolemia could be responsible for the development of atherosclerosis.

Key words: swine, arteriosclerosis, hypoxia, culinary fats, vitamin $\mathrm{D}_{3}$. 